\title{
Dy-Ti (Dysprosium-Titanium)
}

\section{H. Okamoto}

The Dy-Ti phase diagram shown in [Massalski2] was a monotectic type with the monotectic temperature at $\sim 1400{ }^{\circ} \mathrm{C}$. The miscibility gap in the liquid phase was speculated to be limited to a narrow range because a miscibility gap was observed in the Gd-Ti system and not in the Er-Ti system (atomic numbers of Gd, Dy, and Er are 64, 66 , and 68 , respectively). A eutectic reaction was shown at $1280{ }^{\circ} \mathrm{C}$.

[2004Bul] doubted the monotectic type of this system because the $\mathrm{Tb}$-Ti system is not a monotectic type (atomic number of $\mathrm{Tb}$ is 65). Figure 1 shows the Dy-Ti phase diagram proposed by [2004Bul], which was determined based on DTA data measured at 18 and 95 at.\% Ti. The eutectic type was concluded because of the characteristic microstructure of the 18 at.\% Ti alloy.

According to the criteria given by [19910ka], however, the opening angle of the $\mathrm{L}+(\beta \mathrm{Ti})$ two-phase field at 100 at.\% Ti in Fig. 1 is too broad. The initial slope of the liquidus is probably much steeper (the opening angle may be about a half). Then, it could be assumed that the phase diagram includes a monotectic reaction, as shown in [Massalski2]. This assumption does not contradict the result of [2004Bul] because a eutectic reaction also exists in the phase diagram. If the monotectic reaction does not exist, as concluded by [2004Bul], there would be a nearly horizontal section in the liquidus curve in the center region of the phase diagram. Further experimental data are needed to reach the conclusion.

\section{References}

19910ka: H. Okamoto and T.B. Massalski, Thermodynamically Improbable Phase Diagrams, J. Phase Equilibria, 1991, 12(2), p 148-168

2004Bul: M. Bulanova, Yu. Podrezov, Yu. Fartushnaya, K. Meleshevich, and A. Samelyuk, Structure and Properties of As-Cast Ti-Dy Alloys, J. Alloys Compd., 2004, 370, p L10-L13

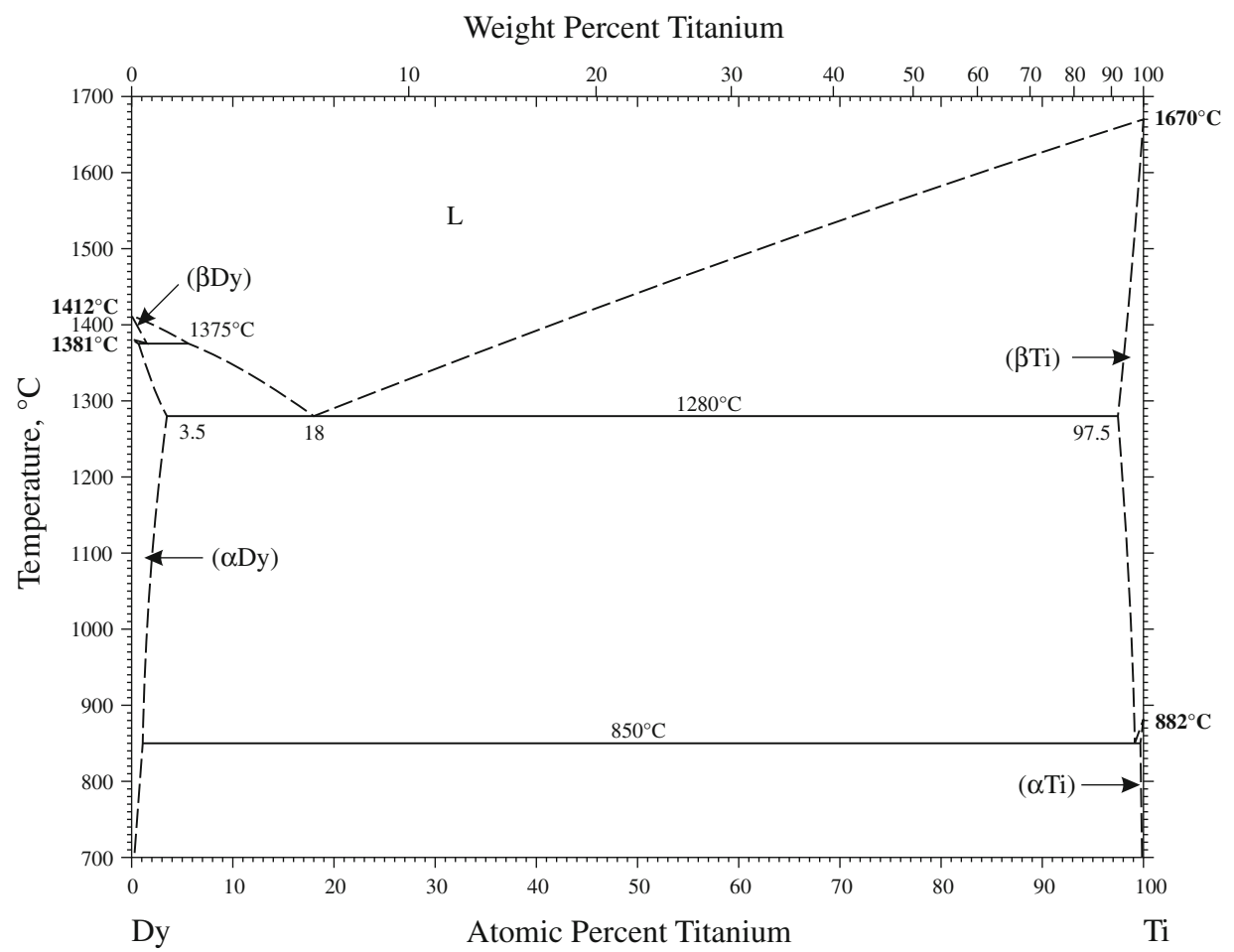

Fig. 1 Dy-Ti phase diagram 